\title{
SER PARA SABER: OS CONCEITOS DE LÍNGUA INGLESA NOS ENTREMEIOS DAS PRÁTICAS PEDAGÓGICAS
}

\author{
To be to know: the concepts of English \\ language within pedagogical practices
}

\author{
Lucas Cardoso MIQUELON \\ Universidade de São Paulo \\ lucas.miquelon@usp.br \\ https://orcid.org/0000-0003-0673-6070
}

\begin{abstract}
RESUMO: Este trabalho objetiva discutir os conceitos de língua inglesa que alicerçam a prática docente num contexto de ensino regular. Partindo da esquematização de Kumaravadivelu (2006), que propõe três conceitos distintos de língua para se pensarem práticas pedagógicas no ensino de inglês, o texto busca fazer uma análise tanto de documentos nacionais norteadores quanto de entrevistas realizadas com professoras da rede pública e privada de ensino. $\mathrm{O}$ percurso investigativo realizado permite refletir que, ainda que se reconheça a importância de enxergar o ensino da língua inglesa a partir de um viés crítico-analítico, especialmente tendo em mente que este é um idioma marcado por processos de colonialidade e violência, a práxis educativa se desenrola através de uma multiplicidade de fatores que, por vezes, encontram-se em posições tensionadas. Nesse sentido, faz-se necessário avançar em formações e repertórios que promovam uma educação linguística em língua inglesa de modo a, ao mesmo tempo, reconhecer o status da língua sem perder de vista os elementos interseccionais que a constituem. PALAVRAS-CHAVE: Educação linguística; Ensino de línguas; Inglês como língua franca.
\end{abstract}

ABSTRACT: This work aims to investigate concepts of the English language which are constitutive of teaching practices in the context of Brazilian regular education. Drawing on Kumaravadivelu (2006), who compares three broad conceptual approaches to language in order to discuss their relevance for learning and teaching practices, this work analyses basic education guiding documents as well as interviews carried out with public and private school teachers. It may be concluded that, despite being possible to recognise the importance of approaching the English language from a critical-analytical point of view - especially bearing in mind that it carries coloniality and vio-

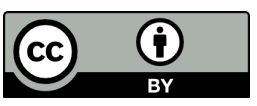


lence in its making and spread, the educational praxis involves a multitude of factors that are oftentimes ambivalent. This is to say that it is paramount not only to invest in teacher education but also to build new repertories grounded on critical English language education fundamentals, so that the status of the English language be considered without disregarding the intersectional elements that engender it. KEY-WORDS: Language education; Language teaching; English as lingua franca.

“[...] sei que não é a língua inglesa que me machuca, mas o que os opressores fazem com ela, como eles a moldam para transformá-la num território que limita e define, como a tornam uma arma capaz de envergonhar, humilhar, colonizar."

hooks (2003, p. 224)

\section{PREÂMBULOS DE UMA QUESTÃO: UM TECER INICIAL}

O que é língua? Uma pergunta que, ainda que tão lacônica, tem a potência de estremecer e causar incômodo - como se verá mais adiante. Trata-se ela de algo que nos é tão constitutivo, tão primeiro, que o mero exercício do questionamento instaura uma inquietação tão enorme quanto aquela que Fernando Pessoa (2013) situacionou e que "fazia-me estremecer os gestos mínimos. Tive receio de endoidecer, não de loucura, mas de ali mesmo".

Uma vez tomada a decisão de iniciar o texto com uma pergunta, coloco-me, igualmente e desde já, numa posição de não oferecer respostas que se proponham universais - aqui, sim, um movimento que recearia de loucura. Buscando-me situar neste "aqui mesmo" de um debate acerca da língua, trago a proposição de Raymond Williams (1977, p. 21) de que "uma definição de língua é sempre, implícita ou explicitamente, uma definição de seres humanos no mundo" (minha tradução) - algo muito similar daquilo proposto por Julia Kristeva (1989), que também aponta para as diferentes possibilidades de se pensar o termo, uma vez que essas possibilidades dependem de conjuntos de conhecimentos que são acionados por diferentes sociedades. Se juntarmos a isso o fato de que o ator, o sujeito - este humano no mundo - também está permeado por outras diversas definições e práticas, temos uma complexidade, um emaranhado de redes de fazer e de ser no mundo que nunca deveria, ao menos a meu ver, ser tirado de uma reflexão. 
Os tecidos poéticos de bell hooks (2003, p. 224) também são costurados ao promoverem um enquadramento de língua que, como o desejo, rebenta: "se recusa a estar contida dentro de fronteiras". Mas, como este exercício metalinguístico ao qual me propus realizar encontra-se irremediavelmente dentro de margens materiais - ainda que, como a narradora de Água Viva (1973, p. 67) nos bem alerta, “o melhor está nas entrelinhas”, avanço a discussão para um patamar de maior palpabilidade a partir de outra pergunta, que complementa a que abre o texto: afinal, qual o conceito de língua inglesa que está embebido nas práticas pedagógicas num contexto de escola regular?

Este texto objetiva transitar por entre os questionamentos levantados acima tendo como base as experiências de estágio realizadas para a disciplina Metodologias do Ensino de Inglês I, da Faculdade de Educação da Universidade de São Paulo. Tais experiências se pautaram em duas frentes de investigação: num primeiro momento, debrucei-me sobre os Parâmetros Curriculares Nacionais para o Ensino Médio (PCNEM) e a Base Nacional Comum Curricular (BNCC) para melhor compreender como esses documentos norteadores apresentam o conceito de língua inglesa dentro de um enquadramento pedagógico voltado para o Ensino Médio. Em seguida, realizei, através da plataforma Google Meet, duas entrevistas semi-dirigidas (cujo roteiro encontra-se disponível na seção de anexos) com professoras de inglês da Educação Básica, sendo uma da rede pública e outra da rede privada de ensino.

O percurso que realizarei neste texto é o que se segue: na primeira seção, ' $O$ eu do texto', eu faço uso de uma narrativa subjetiva que me é constitutiva para refletir o quanto estamos, enquanto sujeitos, embebidos na problemática acerca da produção científica e como aquilo que escrevemos está sempre permeado por tudo que carregamos. Na seção 'Os conceitos de língua', eu proponho uma revisão a partir de Kumaravadivelu (2006) no que tange a três perspectivas de língua: língua enquanto sistema, enquanto discurso e enquanto ideologia, fazendo algumas costuras teóricas com outros autores importantes para pensar a necessidade de discutir o que constitui a língua dentro de possíveis práticas de educação linguística em língua inglesa. Em seguida, na seção 'Nas margens do teórico', eu busco analisar como os documentos educacionais norteadores movimentam o conceito de língua inglesa para, na seção 'O conceito de língua na experiência docente', fazer uma análise das entrevistas realizadas de modo a refletir e tensionar as discussões realizadas até então a partir da prática docente acionada. Por fim, na seção 'Em vias de um esperançar', eu busco desenhar uma reflexão crítica a partir daquilo que foi discutido.

\section{O EU DO TEXTO: UMA NOTAÇÃO}


Dentro da minha experiência enquanto estudante (seja através do ensino regular, seja através da escola a partir da qual acessei o idioma), meu processo com a língua inglesa foi pautado por diversas regras muito bem estabelecidas e que deveriam ser seguidas a fim de que eu alcançasse uma posição aceitável dentro de uma faixa de ‘domínio' da língua. Para que esse 'domínio' se fizesse bem-sucedido, era necessário que eu seguisse um determinado paradigma bastante específico: o objetivo, ora, era aproximar a minha produção (principalmente oral) daquela de um "nativo" - uma categoria deveras estática que significava, em suma, dois grupos sociais: estadunidenses ou britânicos. Este caráter estático, inclusive, limitava-se a recortes bastante restritos do que seriam produções (tanto orais quanto escritas) estadunidenses e britânicas, deixando de lado toda uma variação linguística que é constitutiva desses territórios.

Quando iniciei meu percurso enquanto professor de inglês, já havia passado por diversas experiências que me mudaram enquanto sujeito: já reconhecia a violência que o colonialismo imprimira nas terras das colônias a partir de genocídio e sangue; já reconhecia, também, que o que entendemos, muitas vezes, por inglês, diz respeito a uma hegemonia bastante específica que, também produto da investida colonial, do imperialismo e do (neo)liberalismo, era apenas uma parte daquilo que abarcava as experiências possíveis de um usuário da língua.

Todavia, dentro daquele enredo específico do qual eu fazia parte, uma compreensão crítica dos supracitados elementos só se fazia possível a partir de um diálogo para comigo mesmo - até porque, numa relação (que se estabelece) mercadológica do inglês enquanto commodity (JORDÃO, 2004), a última palavra é a do cliente e, quando menos esperava, vi-me gritando sozinho para os ecos de um sujeito que, incapaz de se adequar a uma lógica que não lhe cabia, era apenas o que restara de um eu-professor, agora fragmentário. Abandonei, ali, a possibilidade da agência do ensino porque acreditei, com uma veemência até assustadora, que eu não possuía o que era necessário - ainda que, por muito tempo, eu sequer soubesse o que era esse "necessário".

Até que, num movimento que me é tão recente quanto potente, fui apresentado a novas possibilidades que me fizeram compreender que o que eu acessei foi, efetivamente, uma hegemonia dentro de uma miríade de cenários possíveis; percebi que aquilo que sentira falta, mas não sabia ouvir no intercalar silencioso dos ecos, era basicamente o reconhecimento de que é possível implodir um inglês para que os vários "inglês-es" possam florescer, a partir de um processo de esgarçamento de construtos hegemônicos coloniais que, por tanto tempo, moldaram as minhas práticas de ensino de inglês - ou, trazendo esse investimento narrativo e reflexivo para mais perto do que objetivo analisar, 
é possível esgarçar, esticar e espremer a língua para entendermos o(s) conceito(s) que a sustenta(m) em determinados contextos. Mas, afinal, que conceitos são esses?

\section{OS CONCEITOS DE LÍNGUA: TRÊS PERSPECTIVAS}

Kumaravadivelu (2006) traz uma contribuição importante e que muito me interessa ao propor três visões que se estabeleceram ao longo do tempo acerca do que é língua. Embora, segundo ele, haja debates infindáveis sobre o que de fato constitui a língua, ele se utiliza de três conceituações específicas pois acredita que tal decurso é caro às reflexões que tangem aos processos educativos em língua inglesa. São elas: (1) língua enquanto sistema, (2) língua enquanto discurso e (3) língua enquanto ideologia. Reconhecendo que este que apresento é um panorama bastante sucinto e reduzido dessas três perspectivas, passemos a elas.

A língua pensada enquanto sistema parte, inicialmente, das contribuições de Ferdinand Saussure, considerado por muitos como o pai da Linguística ao, de certa forma, trazer o estatuto de ciência à disciplina. Dentro dessa perspectiva, a língua é entendida como um sistema já estruturado que é formado por outros subsistemas que a constituem, tais quais o fonológico, o semântico e o sintático. Como Kumaravadivelu (2006) explica, o usuário passa a se utilizar de combinações de fonemas para formar palavras, que formam frases, que formam orações que, por sua vez, formam textos orais ou escritos. Há, portanto, uma ideia de sistematicidade que é fundamentalmente inerente a esse paradigma. Além disso, outro ponto essencial para o entendimento dessa visão é o de que os sentidos são dados a partir da diferença, isto é, x é x porque não é y.

Noam Chomsky, filósofo e linguista estadunidense, também aciona o conceito de língua enquanto sistema, oferecendo outras reflexões à luz daquilo proposto por Saussure. Ele traz a noção de que todos os seres humanos possuem uma faculdade linguística inata, um estado inicial de um sistema linguístico que ele chama de Gramática Universal (GU). Ademais, Chomsky propõe uma separação entre competência e performance - a primeira sendo o conhecimento de língua que um falante-ouvinte carrega e a última sendo o uso da língua nas situações concretas.

Chomsky deixa explícito que tal teoria linguística tem como foco um "falanteouvinte ideal" (CHOMSKY, 1965, p. 3) dentro de uma comunidade linguística homogênea que não recebe nenhum tipo de interferência. Isso significa dizer que Chomsky, assim como Saussure, não se debruça sobre o aspecto pragmático da língua - ainda que isso não signifique dizer que ele não reconheça sua importância (KUMARAVADIVELU, 2006). O ponto é que Chomsky está pensando língua a partir de um viés psicológicoRevista X, v. 16, n. 6, p. 1658-1683, 2021. 
cognitivo, não como "uma ferramenta comunicativa para interação social" (ibidem, p. 7). É a partir desse momento que entra em cena a segunda perspectiva, que pensa a língua para além de um sistema ao reconhecer que ela é, também, discurso.

Nesse paradigma, o sujeito passa a ter uma agência importante e a língua não mais é tida como um sistema de sentidos já prontos, unívoco. O foco, então, torna-se o uso da linguagem dentro de uma "unidade contextualizada" (ibidem, p. 8). Outro fato de importante notação é o de que, em meados dos anos 70, a linguística começa a receber influência de teorias sociais e, com o surgimento da sociolinguística, a língua é enxergada como uma construção social, ou seja, ela deixa de representar a realidade para construíla, dentro de uma multiplicidade de sentidos possíveis.

Não obstante esse passo que é dado com a perspectiva de língua enquanto discurso, McCarthy e Carter (1994) apontam que existem operações linguísticas na interface com aspectos culturais e ideológicos que são cruciais para a produção de sentido. Ainda assim, muitos analistas de discursos acabaram não se voltando a essas operações - um desafio que foi abraçado, segundo Kumaravadivelu (2006), pela teoria crítica, que se deu conta do quanto a língua é capaz de revelar visões de mundo e do quão intrinsecamente relacionada ela está a questões interseccionais.

Trata-se, a perspectiva de língua enquanto ideologia, de pensar e investigar como os sentidos são produzidos a partir de uma diversidade de contextos e de formas simbólicas que mobilizam valores e visões de mundo específicas (THOMPSON, 1990). O antropólogo Kroskrity (2000) aponta para quatro dimensões que nos ajudam a compreender melhor a relação entre língua e ideologia. O quadro abaixo pode ser pensado como um esboço feito a partir da contribuição de Kroskrity (2000) dentro do recorte trazido por Kumaravadivelu (2006). As palavras-chave foram propostas por mim a partir de uma interpretação própria, de modo a condensar os principais pontos discutidos. Pensar nesses quatro conceitos-chave propostos nos oferece elementos importantes acerca da perspectiva de língua como ideologia haja visto que todos eles estão implicados nas práticas subjetivas e objetivas dos sujeitos no dia a dia. 
Tabela 1: Dimensões que perpassam a relação entre língua e ideologia. Esboço feito pelo autor.

\begin{tabular}{|c|c|}
\hline Conceito-chave & Ideologias linguísticas como... \\
\hline PODER & $\begin{array}{c}\text {... compreensões de língua e } \\
\text { discurso pautadas por interesses } \\
\text { de grupos específicos, que } \\
\text { estabelecem determinadas leituras } \\
\text { de mundo - que, por sua vez, } \\
\text { passam a ser lidas como naturais }\end{array}$ \\
\hline INTERSECCIONALIDADE & $\begin{array}{l}\text {... múltiplas ao passo de } \\
\text { que também o são os vários } \\
\text { marcadores sociais que } \\
\text { constituem o sujeito: raça, classe, } \\
\text { gênero, sexualidade, geração, } \\
\text { deficiência etc. }\end{array}$ \\
\hline PERCEPÇÃO & $\begin{array}{c}\text {... variáveis a depender da } \\
\text { percepção dos falantes-ouvintes } \\
\text { acerca das produções ideológicas } \\
\text { que constituem a língua. }\end{array}$ \\
\hline MEDIAÇ $\tilde{A} O$ & $\begin{array}{l}\text {... mediadas pela produção, pela } \\
\text { construção e pela compreensão } \\
\text { das ideologias que permeiam a } \\
\text { língua na relação com o outro e } \\
\text { com o social. }\end{array}$ \\
\hline
\end{tabular}

Fonte: Kroskrity (2000); Kumaravadivelu (2006).

Nesse sentido, as contribuições de Fairclough (1992) também são relevantes para a reflexão, principalmente na medida em que dialogam com aquilo proposto por McCarthy e Carter (1994) e por Kroskrity (2000). Fairclough constata que, durante os anos 50, estabelece-se uma noção de discurso de contornos mais tradicionais, pautados em preceitos estruturalistas. Ele, por outro lado, busca pensar discurso enquanto um movimento de ação para com o mundo que visa à produção de mudanças: ele explica que sua proposição é pensar o uso da língua "como uma forma de prática social, em vez de uma atividade puramente individual ou um reflexo de variáveis situacionais"1 (FAIRCLOUGH, 1992, p. 63, meu itálico).

\footnotetext{
${ }^{1}$ Do original, "[...] as a form of social practice, rather than a purely individual activity or a reflex of situational variables".
} 
Desse modo, se discurso é social e não meramente individual, há, também, uma "relação dialética" (ibidem, p. 64) entre o discurso e a estrutura social: o discurso passa a ser influenciado e moldado por estruturas sociais - o que significa dizer, em última instância, que ele é capaz de produzir identidades sociais, relações sociais entre pessoas e sistemas de conhecimento e crenças (ibidem). Em síntese, pode-se afirmar que Fairclough pensa discurso como um modo de prática política e ideológica.

Nesta esteira de reflexões, Canagarajah e Wurr (2011), ao aventarem uma perspectiva de aquisição de língua partindo de comunidades multilíngues, também enxergam a língua como uma forma de prática social que se faz a partir de um paradigma multilíngue emergente, em vez de um paradigma tradicional calcado no mito do monolinguismo tão reiterado por sociedades ocidentais.

Michel Foucault (1980), nessa mesma linha, não separa a prática do discurso nem a ação do pensamento; discurso, nessa perspectiva, é o agir no mundo, sendo a produção de sentido não pautada necessariamente pelo seu conteúdo, mas pela posição do sujeito que fala. Seguindo essa linha de raciocínio, ele conclui que a verdade é produzida no e através do discurso, pois é "uma coisa desse mundo" (FOUCAULT, 1980, p. 131). Uma vez que a construção da verdade se relaciona aos efeitos de poder que são produzidos e exercidos, cada sociedade possui seu "regime de verdade", isto é, um conjunto de discursos que são aceitos como verdadeiros em oposição àqueles tidos como falsos.

Nesse sentido, e respaldando-me no pressuposto de que o sentido é produzido não simplesmente a partir do seu conteúdo, mas a partir da intersecção de posições enunciativas, é seguro voltarmos às quatro dimensões que citei acima, a saber, poder, interseccionalidade, percepção e mediação para conjecturarmos acerca da infinitude de elementos que estão implicados quando falamos sobre língua. Mas isso importa para enquadramentos pedagógicos e educacionais? Não só importa como se configura como um elemento primordial na prática docente. Se já compreendemos o quanto há por trás das escolhas e das práticas que realizamos, não podemos deixar de refletir, dentro da prática docente, quais são os preceitos que carregamos conosco e a partir de qual perspectiva partimos no momento em que trazemos a língua inglesa para a sala de aula.

Assim como argumenta Ferraz et al. (2019), uma educação em língua estrangeira que se proponha crítica deve ter como foco quem são "os sujeitos, seus desejos, emoções e sua formação cidadã", a partir de uma ideia de corpo que é visto como lugar de liberdade e transgressão (HOOKS, 2004, apud FERRAZ et al., 2019) e de "uma constante problematização da realidade por meio da língua e do corpo" (PENNYCOOK, 2006, p. 60, apud FERRAZ et al., 2019). Se acrescentarmos a isso mais uma especificidade, 
que é a de que a língua inglesa é hoje a língua mais falada no mundo (WHAT..., 2020), faz-se necessário pensar criticamente como esta, que também é "a língua da conquista e da dominação" (HOOKS, 2003, p. 224), está reverberada nas práticas pedagógicas e de que forma a perspectiva de língua enquanto ideologia pode nos oferecer caminhos para exercer uma educação linguística crítica em língua inglesa que considera as relações estabelecidas entre sujeito e língua de modo a promover um ensino de inglês que seja caro não só à formação escolar, mas também à formação cidadã.

Mas, para a construção de caminhos e de novas potencialidades, é sempre importante nos debruçarmos sobre aquilo que já se apresenta na concretude das práticas para que pensemos quais são os marcos e quais são os entraves que se colocam diante de uma educadora - em formação ou já atuante. Dessa forma, proponho analisar, na seção seguinte, dois documentos que norteiam o ensino para o Ensino Médio, a saber, Parâmetros Curriculares Nacionais para o Ensino Médio (PCNEM) e a Base Nacional Comum Curricular (BNCC), para, por fim, enveredar por entre os discursos das professoras aos quais tive acesso.

\section{NAS MARGENS DO TEÓRICO: OS FUNDAMENTOS TRAZIDOS PELOS PCNEM E PELA BNCC}

Do ponto de vista cronológico, a Lei de Diretrizes e Bases da Educação Nacional (LDBEN) foi aprovada em 20 de dezembro de 1996. Os PCN voltados ao Ensino Fundamental se consolidaram em 1997 e, em 2000, foram lançados os PCN direcionados ao Ensino Médio (BRASIL, 2021). De modo geral, eles serviram como referenciais importantes no subsídio à elaboração curricular nacional, ainda que não tivessem a força de lei. Em 2018, quase 20 anos depois, a BNCC foi homologada e implantada. Diferentemente dos PCN (que serviam, como o nome sugere, como parâmetros), a BNCC se instituiu efetivamente como um documento normativo legal que passou a fornecer uma base curricular que deveria ser seguida em todo o território nacional. Dessa forma, é interessante realizar um investimento comparativo entre ambos, BNCC e PCN, para compreender quais foram as progressões engendradas dentro desse ínterim especificamente no que tange ao conceito de língua inglesa.

No caso dos PCNEM, não há uma reflexão reservada apenas à língua inglesa, mas às "línguas estrangeiras modernas" como um todo - ainda que o inglês e o espanhol sejam o foco da descrição. Um ponto que se repete e é reforçado ao longo do texto diz respeito à necessidade de buscar novos olhares e novas abordagens para o ensino dessas línguas, isto é, entender que há muito mais neste tipo de disciplina do que historicamente 
lhe foi atribuído: "deixa de ter sentido o ensino de línguas que objetiva apenas o conhecimento metalinguístico e o domínio consciente de regras gramaticais" (BRASIL, 2000 , p. 26). Mais adiante, explicita-se que uma perspectiva atual tem como "princípio geral levar o aluno a comunicar-se de maneira adequada em diferentes situações da vida cotidiana" (ibid.).

Ao abordar as competências e habilidades esperadas nas disciplinas de "línguas estrangeiras modernas", o texto aponta que, à época, ainda se prezava muito pelo domínio do sistema formal da língua que tinha por base um apego rígido a preceitos normativos de gramática - que, por sua vez, diziam respeito apenas a um "estudo abstrato do sistema sintático ou morfológico" (ibidem, p. 29). É por isso que os parâmetros defendem o exercício de uma série de competências a serem dominadas de modo a favorecer uma "competência comunicativa" maior, partindo de elementos tais quais: o reconhecimento de variantes linguísticas e dos diferentes registros que constituem a comunicação; introduzir aspectos sociais e culturais para pensar determinadas expressões, bem como promover uma reflexão acerca de quem produz o enunciado; utilizar-se de estratégias, tanto verbais quanto não-verbais, para reduzir ruídos na comunicação, dentre outros.

Outro ponto que se sobressai nos parâmetros curriculares é a proposta de pensar as disciplinas de "línguas estrangeiras modernas" a partir de um viés interdisciplinar (este termo não é usado; portanto, trata-se de uma interpretação que eu desenho): reforçase a importância de largar uma compartimentalização que separa as disciplinas para se pensarem projetos que tenham conteúdos integrados, de modo a trazer um contexto mais adequado para aquilo que se ensina. Assim, "a aprendizagem passa a ser vista [...] como fonte de ampliação de horizontes" (ibidem), uma vez que isso, segundo o argumento do texto, permitiria às alunas uma reflexão não só sobre sua própria cultura como também sobre aquelas que estão em seu entorno social, estabelecendo novos vínculos a partir das comparações possíveis entre diferentes povos.

Tendo por base a discussão proposta na seção anterior, julgo estar explícito que os PCNEM, num primeiro momento, trazem um posicionamento crítico a uma abordagem que pensa a língua apenas como sistema, que estaria deslocada da realidade e do mundo social. Ao reforçar a necessidade de se ensinar a língua tendo em mente uma contextualização e uma reflexão acerca de quem fala e de onde se fala, tal abordagem se aproxima muito da perspectiva de língua enquanto discurso - que, retomando Kumaravadivelu (2006, p. 8), pensa a língua a partir de seus usos dentro de uma "unidade contextualizada".

Quando passamos para a BNCC, o caráter formativo presente nos PCNEM, que se propõe mister para essas disciplinas, mantém-se presente e reiterado. Todavia, há uma 
mudança que considero significativa e que demarca a transição de paradigma entre o documento produzido no ano 2000 e este: o fato de que a aprendizagem de inglês passa a ser inscrita numa "perspectiva de educação linguística, consciente e crítica, na qual as dimensões pedagógicas e políticas estão intrinsecamente ligadas” (BRASIL, 2019, p. 241).

Esta é uma mudança significativa, que se estrutura a partir de três implicações: a primeira diz respeito à necessidade que se tem de "rever as relações entre língua, território e cultura" (ibidem), uma vez que, com a expansão da língua inglesa, seu uso deixou de ser restrito a grupos sociais específicos - o que, como o texto aponta, "provoca uma série de indagações, dentre elas, 'que inglês é esse que ensinamos na escola?"' (ibidem). A segunda implicação aborda a defesa dos multiletramentos, isto é, trabalhar, usar e apropriar-se da língua a partir de diferentes "semioses e linguagens (verbal, visual, corporal, audiovisual), em um contínuo processo de significação contextualizado, dialógico e ideológico" (ibidem, p. 242). Por fim, a terceira implicação propõe uma compreensão de língua que transcende determinadas normatividades, ou seja, faz-se necessário implodir ideias pré-concebidas e naturalizadas acerca da língua de modo a relativizar visões como a de que "há um 'inglês melhor' para se ensinar, ou um 'nível de proficiência' específico a ser alcançado pelo aluno"” (ibidem).

Levando em conta a supracitada indagação, a saber, "que inglês é esse que ensinamos na escola?", o texto traz uma reflexão que pode ser vista em sua função dialógica e crítica com aquilo proposto nos PCNEM: o termo "língua estrangeira", usado por este, é tido como insuficiente pela BNCC, especialmente por ser uma terminologia que possui um "viés eurocêntrico" (ibidem, p. 241). É diante desse cenário que o documento "prioriza o foco da função social e política do inglês e, nesse sentido, passa a tratá-la em seu status de língua franca" (ibidem, grifos do texto).

Alves e Siqueira (2016, p. 424) explicam que a perspectiva do inglês enquanto língua franca (ILF) possibilita encará-lo como uma "língua de contato que não depende das normas dos falantes nativos", promovendo uma significativa desterritorialização de uma língua cuja premissa parte de uma negociação mútua constante entre suas usuárias. Ademais, "o inglês com sua função de língua franca é um recurso vibrante, poderoso e versátil, cujo objetivo está centrado na comunicação, inteligibilidade e eficiência" (ibidem, p. 425). É válido ressaltar que o ILF não se configura nem se propõe a ser uma variante do idioma (ainda que, nos seus primórdios, por volta da década de 80 , houve um forte investimento de pensá-lo através um viés mais normativo e regrado a partir 
de definições sintáticas, fonológicas e morfológicas ${ }^{2}$ ). Trata-se, como as autoras bem nomeiam, de um recurso - ou, ainda, uma atitude perante a língua.

Se nos deslocarmos para o contexto educacional e das práticas pedagógicas, esse tipo de perspectiva exige, como a BNCC constata, uma "atitude de acolhimento e legitimação de diferentes formas de expressão na língua” (BRASIL, 2019, p. 242), permitindo que aquele monumento rígido e violento de língua, que faz ode a um arquétipo de "falante ideal", venha abaixo para permitir que outras formas, outras expressões e outras subjetividades possam se repertoriar da língua - emprestando o termo de Canagarajah e Wurr (2011). Dito de outro modo, esse repertoriar-se da língua, especialmente no contexto educacional, estabelece uma nova relação entre usuária e língua na qual a primeira deixa de ser moldada à sombra da última e passa a se apropriar, apoderar e empoderar dela para que ela sirva não como ferramenta de dominação, mas de expressão de um eu que é fundamentalmente plural e complexo.

Nesse sentido, penso ser importante tensionar os elementos trazidos por ambos os documentos trabalhados nesta seção: tanto os PCNEM quanto a BNCC apontam para a necessidade de ultrapassar determinados preceitos que já não cabem mais em um contexto de ensino de inglês: enquanto, nos PCNEM, tem-se a necessidade encarar a língua para além da perspectiva de sistema abstrato de modo a colocá-la em situação de contextualidade, a BNCC sublinha a importância de transpassar a margem do contexto e exercitar, para com ele, um olhar crítico e político, trazendo a perspectiva de ILF como forma de dar conta das multiplicidades intrínsecas às sociedades tais quais elas se apresentam hoje.

Essa constatação demonstra como ambos os documentos apresentam marcos importantes, cada qual a sua maneira, e expressam-se enquanto produtos de seu tempo. Não obstante, sublinho a necessidade de exercitar um olhar crítico e reflexivo para tais produções. Isso significa dizer que, ainda que a BNCC proponha uma abordagem que parte da perspectiva de ILF, não é sensato atribuir-lhe uma condição sine qua non de diretriz mais apropriada quando comparada aos PCNEM.

Santana e Kupske (2020) evidenciam essa problemática ao analisarem a mudança de termos ligados à língua inglesa nos documentos norteadores. Como expus acima, nota-se uma mudança quanto ao status da língua inglesa com a chegada da BNCC: se, nos PCNEM, utiliza-se o conceito de "língua estrangeira", na última versão publicada da BNCC, o conceito utilizado é o de ILF. Santana e Kupske propõem que esta mudança de

\footnotetext{
2 Jenkins (2015) esmiuça esse processo pelo qual o ILF passou, destacando as principais características e movimentos até o termo ser o que atualmente conceituamos.
}

Revista X, v. 16, n. 6, p. 1658-1683, 2021. 
paradigma seja analisada a partir de um viés crítico, uma vez que, com o estabelecimento da perspectiva de ILF tal qual ela foi proposta e redigida na terceira versão da BNCC (2019), tem-se uma exclusão sistemática da oferta de outras línguas, tais quais o espanhol - que era constitutivo dos PCNEM. A autora e o autor argumentam que

"embora esse termo [ILF] supostamente esteja desvinculado dos imperialismos, normalmente atribuídos ao termo língua estrangeira ou à adoção do padrão nativo como alvo de ensino, escolher a língua inglesa como possibilidade única pode revelar justamente uma leitura imperialista, impositiva do inglês frente às outras línguas (SANTANA; KUPSKE, 2020, p. 162).

Cria-se, portanto, o que Santana e Kupske chamam de "o paradoxo das exclusões" (ibid.), já que, embora a BNCC tensione o conceito de "língua estrangeira" justamente por este responder a um contexto eurocêntrico, introduzir a língua inglesa como única no currículo indica, outrossim, um viés exclusivista que contraria "a realidade de muitos alunos brasileiros que vivenciam zonas de contato e de conflito entre línguas" (ibid., p. 161).

Assim, se tomarmos a língua como uma forma de prática social, como proposto por Fairclough (1992), entendemos, como explicitado na seção anterior, que o discurso atravessa e é atravessado pelas estruturas sociais, de modo a produzir diversos sentidos que, por sua vez, traduzem práticas políticas e ideológicas. Dessa forma, estes documentos, registros circunscritos em seus espaços e tempos específicos, devem ser lidos sempre em relação dialógica com os contextos nos quais estão inseridos. Mas o que dizer acerca do contexto escolar? Resta-nos, ainda, um exercício importante de vestir as lentes da práxis pedagógica e questionarmo-nos: como (ou se) a prática, no chão da escola, dá conta da teoria?

\section{O CONCEITO DE LÍNGUA NA EXPERIÊNCIA DOCENTE: ENTRE QUE- BRAS E TEMORES}

Como explicitado anteriormente, duas foram as professoras que se propuseram a conversar acerca do ensino de língua inglesa, compartilhando experiências próprias e respondendo a perguntas específicas. As entrevistas, que foram semi-dirigidas e cujo roteiro encontra-se nos anexos, tiveram uma duração aproximada de uma hora. Com a devida permissão de ambas as participantes, as conversas foram gravadas para, em seguida, serem transcritas. As identidades, os locais de trabalhos e outros elementos que possibilitariam uma possível identificação foram suprimidos, de modo a respeitar o 
anonimato que lhes foi garantido a priori. Ambas as participantes assinaram um Termo de Consentimento Livre Esclarecido, em formato digital. Abaixo, disponibilizo uma tabela com os principais dados referenciais fornecidos pelas professoras, para que seja possível acessar suas realidades de ensino de modo mais efetivo.

Tabela 2: Resumo das principais informações das professoras entrevistadas.

\begin{tabular}{|c|c|c|}
\hline Rede & R.* & B.* $^{*}$ \\
\hline $\begin{array}{c}\text { Experiência } \\
\text { profissional }\end{array}$ & $\begin{array}{c}\text { Voluntária; } \\
\text { escolas de } \\
\text { idiomas (três, ao } \\
\text { total); colégios } \\
\text { particulares }\end{array}$ & $\begin{array}{c}\text { Escolas } \\
\text { municipais e } \\
\text { estaduais }\end{array}$ \\
\hline $\begin{array}{c}\text { Atualmente, } \\
\text { leciona em }\end{array}$ & $\begin{array}{c}\text { Duas escolas } \\
\text { privadas } \\
\text { bilíngues }\end{array}$ & $\begin{array}{c}\text { Uma escola da } \\
\text { rede municipal } \\
\text { e uma escola da } \\
\text { rede estadual }\end{array}$ \\
\hline $\begin{array}{c}\text { Regiões nas } \\
\text { quais as } \\
\text { escolas estão } \\
\text { localizadas }\end{array}$ & $\begin{array}{c}\text { Zonas Oeste } \\
\text { e Sul de São } \\
\text { Paulo - Regiões } \\
\text { tidas como } \\
\text { nobres }\end{array}$ & $\begin{array}{c}\text { Zona Leste de } \\
\text { São Paulo - } \\
\text { Região tida } \\
\text { como periférica }\end{array}$ \\
\hline $\begin{array}{c}\text { Anos escolares } \\
\text { para os quais } \\
\text { leciona }\end{array}$ & $\begin{array}{c}\text { Ensino } \\
\text { Fundamental I, } \\
\text { II e Médio }\end{array}$ & $\begin{array}{c}\text { Ensino } \\
\text { Fundamental II } \\
\text { e Médio }\end{array}$ \\
\hline
\end{tabular}

Fonte: Elaborado pelo autor.

Uma vez que a proposta do texto é pensar o conceito de língua inglesa que atravessa a experiência e as práticas das professoras, este será o recorte pelo qual transitarei, ainda que o material coletado apresente outras potencialidades em sua constituição - as quais não esmiuçarei a fim de estabelecer não só uma economia textual como também uma linha de raciocínio mais direcionada.

Logo no abrir do texto, observei que a pergunta “o que é língua?" tem o poder de estremecer e incomodar. Reitero isso não somente porque respondê-la exige, por definição, toda uma movimentação teórica que dê conta de, ao menos, iniciar uma discussão; de fato, em ambas as entrevistas, houve um momento específico que julguei Revista X, v. 16, n. 6, p. 1658-1683, 2021. 
apropriado no qual direcionei esta mesma pergunta às professoras. $\mathrm{O}$ silêncio que sucede a interrogação e a interrupção de um fluxo de diálogos que, até então, se fazia fluido e um incômodo quase palpável são elementos que já denotam e significam algo: o quanto nós, inscritas em uma práxis pedagógica, refletimos sobre a língua? E isso não quer dizer que haja algo de deslocado dessa atitude das professoras: fosse eu ali o outro quadrado digital, reagiria da mesma forma, com o mesmo espanto, pois o questionamento do que constitui a língua - ou, mais uma vez retomando o que a BNCC traz, "que inglês é esse que ensinamos?", também me é novo.

Para responder à pergunta, R. utilizou-se de sua bagagem teórica, muito provavelmente aquela a que teve acesso enquanto estudante de graduação em Letras: "[tem a] diferença entre língua e linguagem e tudo mais. Acho que a língua, ela ali, é o conjunto de, de elementos, né? Que a gente tem para interagir um com o outro". Pode-se supor que, num primeiro momento, há o acionamento de uma visão de língua que parte da dicotomia langue e parole saussuriana (FIORIN, 2007), o que se aproxima mais da ideia de língua enquanto sistema. Todavia, mais adiante, R. passa a explicar que a possibilidade de falar um outro idioma, no caso o inglês, configura-se como uma "ferramenta para interagir não só com os seus compatriotas, mas também com outros países [...] passei a expandir minha mente, porque eu tenho muito mais ferramentas para pensar".

Partindo da proposição de Kumaravadivelu (2006), é possível identificar, nessa fala da professora, uma mudança de perspectiva, uma vez que a língua deixa de ser pensada como um sistema fechado e abstrato e passa a abarcar outras variáveis. R. reforça, em diversos momentos, o quão potente é o aprendizado de uma língua como o inglês no exercício de expansão de pensamento que visa a um acesso a outros povos e outras culturas - perspectiva que não só se aproxima mais da ideia de língua enquanto discurso como também dialoga diretamente com aquilo proposto pelos PCNEM.

Entretanto, não são os PCNEM que R. aciona, mas a BNCC:

a gente se pauta muito na BNCC e a BNCC, pra língua estrangeira, ela foca não só na habilidade linguística, né? Ela tem aquela coisa da leitura crítica, do desenvolvimento de ideias, do debate e eu acho que hoje - é o que eu vejo na minha realidade - é o ensino do inglês que quer muito sair do livro, né?

Nesse movimento trazido por R., ela aponta a BNCC como uma diretriz importante para o seu trabalho docente e salienta a necessidade de realizar uma leitura crítica e desenvolver ideias a partir do debate com estudantes. Aliás, outro elemento que se coloca em congruência àquilo abordado pela $\mathrm{BNCC}$ é a prática e o ensino de um 
inglês que lance mão não de uma falante ideal, mas de uma usuária que utiliza a língua dentro de suas próprias possibilidades de modo a promover uma comunicação efetiva. Para exemplificar esse ponto, ela faz uso do ensino dos fonemas $/ \theta / \mathrm{e} / \mathrm{\partial} /$ - que, dentro de diversos contextos de sala de aula, apresentam-se como uma "dificuldade" comum de estudantes. Ela afirma que

[o inglês é] uma língua que é, que é global nesse sentido da comunicação. E existem implicações pro ensino de fonética, por exemplo. Eu não passo horas da minha vida ensinando a diferença do som do "th", sabe? Eu ensino, eu mostro. Mas eu vou ficar corrigindo por quê? [...] $\mathrm{O}$ que.... o que eu quero? Eu quero que esse aluno pense em inglês, que ele faça debates, que ele faça projetos, que ele se comunique da forma que ele puder, ou eu quero que ele fique fazendo exercício para entender quando que eu tenho o "th" que é voiced?

Há, por parte da professora, uma atitude de legitimação de possíveis formas de expressão na língua que rompam com ideias pré-concebidas tais quais "precisão" e "falante ideal", dando vazão a um foco que visa à inteligibilidade e à comunicação efetiva. Esse é um tipo de posição que diz respeito ao ILF enquanto uma atitude perante a língua na qual a correção excessiva, a partir de um inglês hegemônico, se desfaz.

A partir daquilo movimentado por R., é também perceptível como, para a professora, ainda há uma relação que se estabelece entre língua, identidade e territorialidade, principalmente quando ela toma o aprendizado do inglês como uma possibilidade de "descobrir que as pessoas pensam diferente" e de entender "a construção da identidade na língua estrangeira". Para elaborar naquilo que propõe, ela narra uma história de quando atuou como intérprete de um missionário estrangeiro. Ela explica que "ele me contou da vida deles, dos problemas enfrentados, e ele não tem os mesmos problemas, as mesmas opiniões, ele não tem as mesmas prioridades, sabe?". Com surpresa, ela aponta que "ele ligou para a esposa dele, mesmo a ligação sendo cara ele disse que ia ligar, e ele falava inglês e francês como se fosse a coisa mais normal do mundo! E eu achei fascinante aquilo".

A convivência com o missionário, nesse sentido, constituiu-se como uma experiência pautada na diferença, isto é, permitiu que R. expandisse seu horizonte a partir do encontro com aquele cuja vivência é externa à sua em diversos sentidos. Igualmente, é possível identificar um estranhamento inicial para com a realidade de uma comunidade multilíngue, que tem por base uma diversidade linguística que se configura como norma, não como exceção (CANAGARAJAH; WURR, 2012). 
Além disso, a percepção que se molda fortemente na relação entre língua, territorialidade e identidade é algo historicamente construído dentro das abordagens e metodologias de ensino de língua; somos, de uma forma ou de outra, atravessadas por essa questão e, dentro de uma práxis pedagógica, talvez seja interessante desenvolver tanto uma criticidade atuante quanto uma reflexividade para com esses pontos e que (1) visem à superação de conceitos tais quais o de "estrangeiridade" e de "língua estrangeira" e, por outro lado, (2) possibilitem uma abertura de horizontes para realidades outras que não estejam estruturadas dentro de uma lógica ocidental e especialmente eurocêntrica de língua e de subjetividade.

Por outro lado, estes são elementos que devem ser analisados a contrapelo pois, como abordado na seção anterior, o fato de a BNCC situar a necessidade de deslocamento de uma visão eurocêntrica de língua não impede que contradições sejam produzidas. Aliás, tomando como base as dimensões que perpassam a relação entre língua e ideologia, tais contradições identificadas no supracitado documento ganham novas camadas.

Silva Júnior e Fernández (2019), ao tratarem da ausência da língua espanhola na BNCC, explicitam como existem interesses de grupos específicos ligados ao mercado que, de uma forma ou de outra, exerceram influência na redação da última versão do documento e que, por conseguinte, construíram um currículo que é, ele mesmo, mediado pelas demandas desses grupos.

Nesse sentido, lançar mão de uma perspectiva de língua enquanto ideologia é, por conseguinte, saber reconhecer os esgarçamentos que constituem a produção dos documentos norteadores, exercitando a capacidade de percepção desses jogos de poder que se instauram nos espaços públicos de modo a não tomar como norma e prescrição algo que efetivamente está alinhado a noções específicas de sociedade e de sujeito.

Caminhando, agora, para a interlocução com a professora B., é possível notar que há, igualmente, uma relação com o estatuto da língua que transita por algumas perspectivas. Ela inicia dizendo que "o idioma não é estático, é dinâmico, muda a todo momento. Então o que é língua? Ação". Partindo dessa fala, é possível inferir que B. está rejeitando a ideia de língua enquanto um sistema abstrato e fechado na medida em que a coloca enquanto um fenômeno mutável que responde às sociedades. O que contribui para um melhor enquadramento acerca de sua visão é o que ela traz acerca do ILF:

Aí você tem que explicar que a língua inglesa é uma língua franca, que é uma língua sem fronteiras, e aí você fala, "tá bom, você não quer viajar para os EUA, mas você pode estar aqui na Argentina, se não souber falar espanhol, mas souber inglês, você se comunica." Você tem que trazer para a realidade deles e ver se assim potencializa. 
O acionamento do ILF, neste caso específico, parte de uma narração na qual ela explica que as alunas, de modo geral, não se interessam pelo idioma. Segundo ela,

se você lecionar algum dia em escola pública, e se for ainda mais nas periferias, você vai ouvir a típica frase: "eu não sei nem português, para quê eu quero saber inglês?" Eles falam isso o tempo inteiro, então, eles falam "eu não vou trabalhar, não vou viajar"; é assim, um pensamento bem limitante.

Ao questioná-la sobre como ela costuma reagir a esse tipo de fala, ela responde que "depende da situação": caso ela entenda o questionamento como sendo um que não precede embate, ela busca explicar que "porque você pode trabalhar, você pode ser abordado, porque você pode pensar que não pode viajar, mas futuramente, você pode viajar". Em casos nos quais ela identifica um "ataque" por parte da aluna, sua resposta à pergunta é a que segue: "eu viro e digo assim, 'não sabe português, porque não QUER, você tem português desde o primeiro ano, você não sabe é porque não quer".

A professora B. justifica que esta é uma postura necessária porque, enquanto professora, precisa se impor perante a sala para que ela seja respeitada, para que ela seja "o rei da selva" de modo a "ganhar a manada porque senão você não consegue. Senão, pronto, vai entrar na sala e eles vão rir da sua cara". B. também aponta que, ainda que o material didático oferecido pelo Governo do Estado - a saber, o Caderno do Aluno - seja bom porque "já vem pronto" e "é um trabalho a menos", ele costuma não condizer "com a realidade da educação brasileira". Trata-se, segundo ela, de um material que tem como foco primordial o entendimento do contexto, mas que ela sente falta da "gramática" ainda que reconheça a importância de trabalhar a língua dentro de um contexto de modo a permitir que as alunas se posicionem.

O problema, segundo ela, é que essa perspectiva não é adequada para situações como as que ela enfrenta, nas quais as alunas não têm um "domínio suficiente" do idioma para poderem se posicionar. Ademais, muitas, segundo ela, "não têm uma opinião formada" sobre os temas tratados e "só recebem e não questionam". B. ainda argumenta que, para além da "dificuldade com a língua", há "falta de interesse, preguiça e eles enxergam a língua como desnecessária. Eles acham que não precisa [aprender]” e que, mesmo quando tenta "mostrar que a língua inglesa pode te abrir portas, alguns alunos te enxergam [...] como arrogante, metida". Ela exemplifica essa fala com uma situação anedótica de quando levou um passaporte para a aula, mas foi recebida com hostilidade por muitas, que apontaram que ela estava "querendo se mostrar". Mais adiante, ela comenta que 
ao invés de entenderem a língua inglesa como um passaporte para muitas coisas - não só passaporte, mas emprego e conhecimento de cultura etc., que seria o potencial da língua, muitos enxergam como uma coisa fora da realidade, e que a gente 'quer ser'. Mas outros enxergam a realidade. Então o que você tenta fazer para intermediar? Você tenta criar situações no cotidiano só para eles saberem "se virar". Se você fala muito em viagem, eles podem olhar como algo negativo. Se você fala pouco, não estimula o sonhar, que é gostoso também estimular, estimular essa vontade. [...] Eu acho que essa visão limitante que aí não é um problema da escola e nem um problema dos professores, mas sim, cultural, é cultural e muito mais regional - é cultural, mas em certas regiões é pior, então regional também.

Muitos são os elementos que podem ser trazidos à tona a partir da contribuição de $\mathrm{B}$. Talvez, o que mais salte à leitura seja a possibilidade de identificação da violência institucional e estrutural que vaza das falas das alunas. É no mínimo inquietante pensar que uma pessoa, que foi sociabilizada sua vida toda dentro de um contexto de língua portuguesa afirme, sem hesitação e repetidamente, que "não sabe nem português". Não só ela está comunicando que não sabe o português através do português, como ela também está explicitando uma angústia em que sua própria experiência de língua é tida como estrangeira para ela mesma. Num contexto como esse, as potencialidades educativas tornam-se cerceadas por um fantasma sempre presente na estrutura de ensino público: o da incapacidade.

Mergulhadas em uma educação bancária (FREIRE, 1997), essas alunas não só são vistas como invólucros vazios que devem ser preenchidos; elas parecem enxergar a si mesmas como invólucros construtivamente irreparáveis que sequer podem ser preenchidos. Trata-se de uma situação de violência epistêmica tão bem-sucedida que as potencialidades possíveis dessas subjetividades são arrancadas pela raiz, deslocando-as de si mesmas.

Julgo importante refletir, a partir de Franz Fanon (2013), sobre como a colonização é, primordialmente, uma situação histórica, não ontológica - uma conjuntura que produz dessemelhança. Quem vive numa cidade pós-colonial, não espera, por definição, gestos de bondade de outrem, uma vez que se conserva uma sensação de que este corpo está tão e somente por ele mesmo. A esse corpo, a essa subjetividade, o que se constitui como "realidade" e "potencialidade" também lhe é estrangeiro - assim como sua própria língua.

Aliás, uma das questões fundamentais que acompanha o trabalho de Fanon é a defesa de que o colonialismo é reprodutor de dessemelhança, ou seja, o sistema colonial produz uma tecnologia de desumanização em um sujeito cuja experiência é pautada pela 
ausência histórica. Num espaço de tantas marcas coloniais como São Paulo, a fisionomia da desumanidade é erguida como monumento invisível: não é o semelhante que é excluído, mas o dessemelhante; a dessemelhança é uma imagem - a imagem de um corpo tido como menos humano.

Embora a perspectiva do ILF seja citada pela professora, é possível perceber que se revigora uma ideia de aprendizado pautada na "adaptação" a uma hegemonia específica, reforçando o senso de deslocamento do sujeito para com a língua: esta se torna um instrumento de acesso ao outro, mas nunca a um "eu" da estudante (BIESTA, 2021) - especialmente porque o que perpassa essa abordagem, ainda que respaldada por uma língua que é contextualizada, é a ausência de criticidade acerca do próprio estatuto da língua e, por conseguinte, da própria posição do sujeito no mundo.

Entretanto, é fundamental saber dosar esse tipo de apontamento. Ainda que eu tenha sugerido uma ausência de criticidade, ela deve ser tomada mais como um sintoma e menos como uma causa; mais como uma tendência observável no todo e menos como uma característica particular de determinado sujeito. Se reforcei constantemente o caráter teórico do exercício que me propus a realizar neste texto, o fiz também não só porque reconheço a limitação na qual esbarro ao identificar dificuldades e premências sem, todavia, necessariamente explorar a fundo caminhos; reconheço, outrossim, que a realidade que está posta nas escolas complexifica enormemente aquilo que é tido como potência. Para que a reflexão e a criticidade acerca do estatuto da língua se façam possíveis, devemos antes nos perguntar quantas foram as profissionais que tiveram acesso a esse tipo de discussão e quais são os entraves que se presentificam no processo de formação de professoras - este que é, ao mesmo tempo, tão estimado e tão desassistido.

\section{EM VIAS DE UM ESPERANÇAR: TO BE TO KNOW}

Kumaravadivelu (2012) aponta que "o inglês não é somente a língua do global, mas é, também, a língua da colonialidade"33 (minha tradução), imposto em diversos territórios através do imperialismo. Em seguida, ele explica que o fato de o inglês ter se tornado dominante linguística e culturalmente possibilitou um exercício crítico-analítico acerca de seu status, de modo a reconhecer as bagagens coloniais e culturais que o uso da língua carrega. Por outro lado, ele aponta, esse movimento também produziu, como resposta, tentativas de "sanitizar" a língua, destacando-a dessas bagagens e legitimando um foco no seu valor instrumental e puramente comunicativo.

\footnotetext{
${ }^{3}$ Do original, "English is not only a language of globality but is also a language of coloniality". 
O percurso realizado neste texto permite que observemos como a práxis educativa se configura a partir de uma multiplicidade de fatores que, por vezes, encontram-se em posições contraditórias e tensionadas. Se, por um lado, é perceptível que duas concepções de língua (enquanto estrutura e enquanto discurso) aparecem, de uma forma ou de outra, nos discursos das professoras entrevistadas, por outro lado, um desafio que está dado é o de promover uma ainda insipiente educação linguística em língua inglesa, isto é, enxergar o ensino e a aprendizagem da língua como movimentos e movimentadores de mundos e que se encontra interligada a uma série de elementos interseccionais que constituem o sujeito.

Ademais, essas contradições e tensões também são observáveis quando nos debruçamos sobre os documentos norteadores: se a BNCC aposta em uma perspectiva de ILF que responde a uma necessidade de desterritorialização da língua e a um reconhecimento do inglês a partir de suas funções social e política, esta mesma perspectiva, quando colocada em comparação àquela trazida pelos PCNEM, deixa entrever um movimento que Santana e Kupske (2020) nomeiam de "paradoxo das exclusões", haja visto que a substituição do status da língua inglesa de "língua estrangeira" para "língua franca" produz a eliminação de processos pedagógicos ligados a outras línguas e estabelece uma exclusividade para com língua inglesa que, paradoxalmente, reforça o caráter hegemônico e de moldes mercadológicos do qual a própria BNCC supostamente tenta se desvencilhar.

Expandindo o escopo de reflexão daquilo abordado no texto, pensar nas contradições dos documentos norteadores é também entender que eles não devem ser reproduzidos sem quaisquer questionamentos - especialmente tendo em mente que (1) eles são produtos de um contexto político, social, histórico e cultural específico que, por sua vez, desempenha um papel significativo da produção de sentidos e de propostas curriculares; e que (2) aquilo que é trazido pelos documentos, especialmente pela BNCC, vezes tantas é impraticável em diversos contextos de ensino (ROCHA; DE MELO, 2019), o que acentua ainda mais a necessidade por processos formativos continuados de professoras (SANTANA; KUPSKE, 2020) - algo que sugeri brevemente na última seção.

Tais processos formativos continuados, inclusive, são necessários também para que as escolhas e ações pedagógicas que realizarmos efetivamente se engendrem a partir de fundamentos teórico-metodológicos robustos e estruturados. Para que as quatro dimensões constitutivas de uma perspectiva de língua inglesa enquanto ideologia - poder, interseccionalidade, percepção e mediação - sejam delineadas e praticáveis dentro da vivência docente, faz-se necessário dar um passo para trás e promover espaços 
pedagógicos reflexivos que partem da nossa própria experiência enquanto sujeitos no mundo, de modo a, numa camada primeira, melhor compreendermos por que carregamos os preceitos que carregamos e, numa camada mais profunda, melhor embasarmos nossos repertórios educacionais e pedagógicos.

É fundamental atentarmo-nos, outrossim, à armadilha da dicotomia a qual me referi anteriormente. Os conceitos de língua que foram movimentados coexistem e, de modo algum, proponho pensar a partir de uma lógica de exclusão de um para a existência de outro - e os relatos das professoras nos deixam entrever como isso, de fato, não é possível. O movimento que talvez ainda se faça necessário, e este é um desafio que coloco a mim e àquelas que leem o texto, é pensar em como, partindo dos três conceitos, podemos esgarçar a contextualidade que hoje conseguimos acessar; não se trata de abandonar um para abraçar outro, mas de realizarmos um exercício reflexivo acerca da própria prática pedagógica e perguntarmo-nos (1) o que, (2) quem, e (3) a partir de que efetivamente estamos ensinando quando tomamos este ou aquele caminho nas infinitas possibilidades que se abrem para a educação linguística em língua inglesa.

Assim como Guacira Lopes Louro (2001) evidencia, estabelecer um estranhamento para com práticas já fossilizadas e que não dão mais conta das múltiplas realidades que são intrínsecas a um cotidiano escolar parece-me um itinerário possível e passível de potencialidades na esteira de reflexões que busquei promover neste texto. Também me parece apropriado, como propõe Ana Paula Duboc (2017), pensar e trazer possíveis brechas a partir de gestos pedagógicos que visam a uma educação libertadora e emancipatória, nos termos de Freire $(1985,1992)$.

Retomando o relato que fiz sobre a minha própria experiência enquanto professor, reflito que aquele eu-professor que me constituiu tão fragmentariamente há alguns anos e que me fez abandonar toda e qualquer possibilidade a partir da língua inglesa hoje se agarra a essas brechas. Assim como Esperanza, a personagem do romance The House on Mango Street (1984), de Sandra Cisneros, "I have gone away to come back" ao perceber que é possível tomar "a linguagem do opressor" (hooks, 2003, p. 233) e voltá-la contra si mesma. Talvez, eu esteja idealizando contextos que sequer acessei; talvez, a estrada se faça muito mais árida que flores. Mas, parafraseando Paulo Freire (1992), por muito tempo, tive esperança do verbo esperar; hoje, luto por uma esperança do verbo esperançar. E lutar, do ponto de vista de um agora e aqui mesmo futuro professor de inglês, é como eu caminho, na esperança de um dia poder olhar nos olhos de uma aluna e, através de uma posição enunciativa de interlocutor, dizer-lhe: você é e você sabe, so that they be to know. 


\section{REFERÊNCIAS}

ALVES, P. C. R.; SIQUEIRA, S. Inglês como Língua Franca: da cena do mundo para a cena da sala de aula. Fólio - Revista de Letras, Vitória da Conquista. V. 8, n.1, jan./jun., 2016, p. 413-434.

AUSTIN, J. L. (1962). How to do things with words. London: Oxford University Press.

BIESTA, G. Reconquistando o coração democrático da educação. Educação Unisinos, vol. 25, 2021. doi: 10.4013/edu.2021.251.01

BRASIL. Ministério da Educação. Histórico. Website Base Nacional Comum Curricular. Disponível em: http://basenacionalcomum.mec.gov.br/historico. Acesso em: 15 de julho de 2021.

BRASIL. Ministério da Educação. Base Nacional Comum Curricular. Brasília, 2019.

BRASIL. Ministério da Educação. Parâmetros Curriculares Nacionais: Ensino Médio. Brasília: MEC/SEF, 2000.

CANAGARAJAH, A. S.; WURR, A. J. Multilingual communication and language acquisition: new research directions. The Reading Matrix, Vol. 11, n.1, 2011.

CISNEROS, S. The House on the Mango Street. New York: Vintage Books, 1984.

CHOMSKY, N. Aspects of the theory of syntax. Cambridge, MA: MIT Press, 1965.

DUBOC, A. P. Letramento crítico nas brechas da sala de línguas estrangeiras. In: TAKAKI, N. H.; MACIEL, R. F. (Orgs.) Letramentos em Terra de Paulo Freire. Campinas: Pontes Editores, 2007. p. 209-229.

FAIRCLOUGH, N. A Social Theory of Discourse. In: Discourse and Social Change. Cambridge: Polity Press, 1992. pp. 62-101.

FANON, Frantz. Os condenados da terra. Tradução de Enilce Albergaria Rocha e Lucy Guimarães. Juiz de Fora: Ed. UFJF, 2013.

FERRAZ, D. M.; FADINI, K.; FERREIRA, D.; REZENDE, T. EELT - Education Through English Language Teaching: Potencialidades e Limitações. In: FINARDI, K. et al. (Orgs.) A Diversidade de Fazeres em torno da Linguagem: universidades, faculdades e educação básica em ação. Campinas: Pontes Editora, 2019. p. 255-268.

FERRAZ, D. M. Visibilidade LGBTQIA+ e Educação Linguística: Por Entre os Discursos Revista X, v. 16, n. 6, p. 1658-1683, 2021. 
de Ódio, Aceitação e Respeito. Revista X, Curitiba, vol. 14, n. 4, p. 200-221, 2019.

FERRAZ, D. M. Educação linguística e transdisciplinaridade. In: PESSOA, R. R.; SILVESTRE, V.; MONTE MÓR, W. (Orgs.). Perspectivas críticas de educação linguística no Brasil: trajetórias e práticas de professoras/es universitárias/os de inglês. São Paulo: Pá da Palavra, 2018, p. 103-117.

FERRAZ, D. Educação crítica em língua inglesa: neoliberalismo, globalização e novos letramentos. Curitiba: Editora CR, 2015.

FIORIN, J. L. Introdução à Linguística I. Objetos teóricos. 5 ed. São Paulo: Contexto, 2007.

FOUCAULT, M. Power/Knowledge: Selected Interviews and Other Writings 19721977. New York: Pantheon, 1980.

FREIRE, P. Papel da educação na humanização. Revista da FAEEBA Salvador, ano 6, n.7, p. 9-32, jan./jun. 1997.

FREIRE, P. Pedagogia da Esperança: um reencontro com a Pedagogia do Oprimido. Rio de Janeiro: Paz e Terra, 1992.

FREIRE, P. Pedagogia do Oprimido. Rio de Janeiro: Paz e Terra, 14a ed. 1985.

HALLIDAY, M. A. K. Explorations in the functions of language. London: Arnold, 1973.

HALLIDAY, M. A. K. Language as a social semiotic. London: Arnold, 1978.

hooks, b. Ensinando a transgredir: a educação como prática da liberdade. São Paulo: Martins Fontes, 2003.

HYMES, D. On communicative competence. In PRIDE, J.; HOLMES, J. (Eds.), Sociolinguistics: Selected readings. Harmondsworth, England: Penguin Books, 1972.

KRISTEVA, J. Language the unknown. New York: Columbia University Press, 1989.

KROSKRITY, P. V. Regimes of language. Santa Fe: School of American Research Press, 2000 .

KUMARAVADIVELU, B. Language Teacher Education for a Global Society. New York: Routledge, 2012. 
KUMARAVADIVELU, B. Understanding Language Teaching: from Method to Postmethod. New Jersey: Lawrence Erlbaum Associates, 2006.

JENKINS, J. Repositioning English and multilingualism in English as a Lingua Franca. Englishes in Practice, 2/3, p. 49-85, 2015.

JORDÃO, C. M. A língua inglesa como commodity: Direito ou obrigação de todos? Conhecimento local e conhecimento universal, v.3, n. 1, p. 272-295, 2004.

LISPECTOR, C. Água Viva. Rio de Janeiro: Rocco, 1973.

LOURO, G. L. Teoria Queer: uma política pós-identitária para a educação. Estudos Feministas, vol. 2, 2001. p. 541-553.

MCCARTHY, M.; CARTER, R. Language as discourse: Perspectives for language teaching. London: Longman, 1994.

PESSOA, F. Livro do desassossego. Porto: Assírio e Alvim, 2013, n. 98.

ROCHA, L.; DE MELO, G. Onde ficam raça e gênero na BNCC do ensino médio? A homogeneização das diferenças. In: GERHARDT, A.; AMORIM, M. (Org.). A BNCC e o ensino de línguas e literaturas. Campinas, SP Pontes Editores, p. 209-238, 2019.

SANTANA, J. S.; KUPSKE, F. F. De língua estrangeira à língua franca e os paradoxos in-between: (tensionando) o ensino de língua inglesa à luz da BNCC. Revista X, v. 15, n. 5, 2020. p. 146-171.

SILVA JÚNIOR, A.; FERNÁNDEZ, G. Ausência da língua espanhol Comum Curricular: quais implicações esperar? In: GERHARDT, A.; AMORIM, M. (Org.). A BNCC e o ensino de línguas e literaturas. p. 181-208, 2019.

THOMPSON, J. B. Ideology and modern culture. Oxford, England: Polity Press, 1990.

WHAT is the most spoken language? Etnologue, 2020. Disponível em: https://www. ethnologue.com/guides/most-spoken-languages. Acesso em: 12 de julho de 2021.

WILLIAMS, Raymond. Marxism and Literature. Oxford: Oxford University Press, 1977. 


\section{ANEXO}

Roteiro da entrevista semi-dirigida

1. Nome

2. Escola(s) em que leciona atualmente

3. Há quanto tempo dá aula de inglês

4. Conte-me um pouco mais sobre sua experiência com o ensino do inglês: escolas de idiomas, escolares regulares - publicas e privadas, aulas particulares

5. Por que decidiu ser professor(a) de inglês?

6. Como tem sido sua experiência de ensino na pandemia?

7. Pensando num contexto em que não há mais pandemia, quais são, na sua opinião, as maiores potencialidades educacionais que o ensino de inglês pode proporcionar?

8. Quais os desafios?

9. Quais sãos os elementos que você considera essenciais, para um(a) estudante, num processo de educação em língua inglesa?

Recebido em: 27 jul. 2021.

Aceito em: 24 set. 2021. 